\title{
E-books on the mobile e-reader
}

\author{
Chulyun Kim, Ok-Ran Jeong*, Jaehyuk Choi and Won Kim \\ Department of Software Design and Management, Gachon University, Seongnam, Korea
}

\begin{abstract}
The market for e-books has been established during the past several years. Many e-book readers are commercially available, and millions of e-book titles are available for purchase or free download. E-paper technology has matured enough to be used as the screen for dedicated e-book readers which make reading possible with the familiar feel of reading printed books. In this paper, we provide a comprehensive review of the status of the e-book, including the architecture and features of e-book readers, market adoption and e-book industry ecosystem.
\end{abstract}

Keywords: E-book, e-paper technology, e-book reader, e-book industry ecosystem

\section{Introduction}

A book organizes texts and images. As texts and images can be stored and retrieved from computers in digital form, the emergence of e-books is only natural. An e-book (electronic book) is a book that is stored in digital form and read on a mobile e-book reader. There are two types of e-book reader: a dedicated e-book reader (such as Amazon's Kindle, Sony's PRS Reader), and a multi-function computing device (such as a PC, a tablet computer, a PDA, a smart phone). (Henceforth, we will use the term "e-book reader" to mean either type where a distinction is not necessary.) Figure 1 shows an Amazon Kindle e-book reader. It has a black-and-white 6-inch display panel and a QWERTY keyboard with navigation buttons. Figure 2 shows an iPad with iBooks. The latest version of iPad has a 9.7-inch LCD touch panel, and iBooks, an e-book reader application, is available for reading e-books.

An e-book may be created from a printed book by reentering the texts and images, or by scanning the contents of the printed book and recreating the texts using OCR (optical character recognition) technology. An e-book may also be created in the absence of a printed book.

There are advantages and drawbacks to e-books over printed books. A computing device for reading e-books can hold many books on the device, and the (human) reader does not need to lug all the printed books. However, a computing device needs electricity, and the screen may cause greater eye strain. As the price, size and weight of the device have become acceptable, and the availability and price of e-book titles have become reasonable, the e-book market has taken shape. Many dedicated e-book readers are on the market. E-book software allows e-books to be read on a PC, a tablet computer, a PDA, a smart phone, etc. Libraries lend e-books. Major publishers distribute e-books through their Web sites. Millions of e-books are also available for free downloading.

A good overview of the e-book and the e-book reader can be seen in $[7,10]$. In this paper, we aim to provide a more encompassing review of the status of the e-book and mobile e-reader, so that it may serve

\footnotetext{
${ }^{*}$ Corresponding author: Ok-Ran Jeong, Assistant Professor, Department of Software Design and Management, Gachon University, San 65, Bokjeong-dong, Sujeong-gu, Seongnam, Gyeonggi-do, 461-701, Korea. E-mail: orjeong@ gachon.ac.kr.
} 


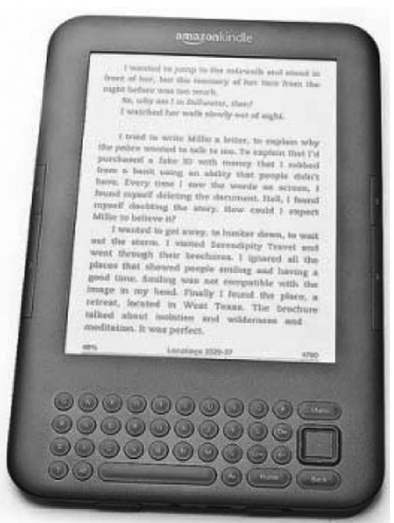

Fig. 1. Amazon Kindle.

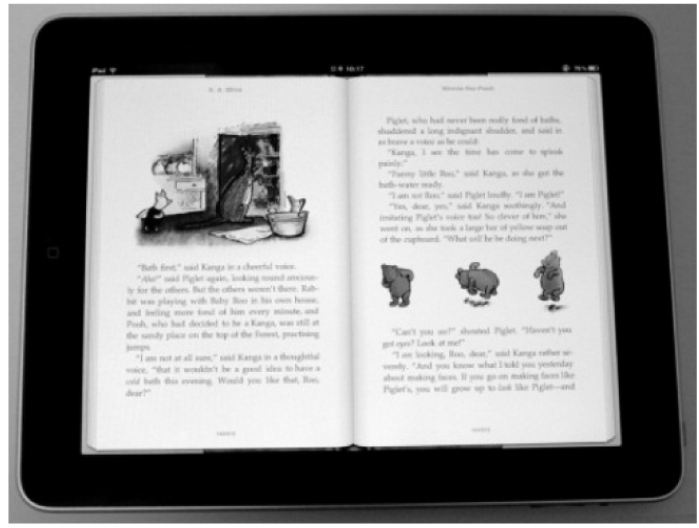

Fig. 2. Apple iPad with iBooks.

as a solid starting point of research and study of e-books. In particular, we review the architecture and features of e-book readers, and the market adoption and industry ecosystem; and examine the market and technology issues.

The remainder of this paper is organized as follows. In Section 2, we review the advantages and drawbacks of e-books over printed books. In Section 3, we discuss the architecture and features of e-book readers. In Section 4, we discuss market adoption and industry ecosystem for e-books. In Section 5, we discuss both marketing and technology issues that pose challenges for market expansion of e-books. In Section 6, we provide a prognosis for e-books, and conclude the paper.

\section{Advantages and drawbacks of e-books}

In this section, we review the advantages and drawbacks of e-books over printed books. They are well-documented in [12] and other articles. In our view, however, some of the statements in these articles need to be qualified, and we try to make them more accurate here.

\subsection{Advantages}

The advantages of e-books over printed books are as follows:

- Some articles claim that "e-books are portable", implying that e-books are more portable than printed books. But a small paperback book can be just as portable as an e-book reader. It is more accurate to say that e-books can be more portable when a person needs to carry many books or a large-size book, since an e-book reader can store many books.

- An e-book can be purchased or borrowed immediately over the Internet at anytime from anywhere. To purchase or borrow a printed book, one must go to a physical bookstore or a library, or must wait for it for days to arrive in the mail.

- E-book readers offer a number of features that help the (human) reader read. E-books can contain rich media, such as audio, video, animation, newspapers, RSS feed, etc. (Printed books certainly do not have such rich media.) Texts and images can be resized, helping people with eyesight difficulties. Font styles can be changed, too. E-books come with a built-in dictionary. (Of course, people can use magnifying glasses to read printed books, can carry a small dictionary, or look up a dictionary from 
a smart phone. But the facilities integrated in an e-book reader are much more convenient.) E-books provide a keyword-based search capability, so that the (human) reader can search for keywords in the entire e-book or even a collection of e-books stored in the e-book reader [4]. E-books also provide text-to-speech translation capability.

- For the publisher, it is in general less expensive to produce and distribute an e-book than a printed book. The publisher has to still bear the cost of producing and marketing the e-book, the royalty payment to the authors, as well as the cost of computers and e-book writing software ${ }^{\mathrm{i}, \mathrm{ii}, \mathrm{iii}}$. However, there are no printing, binding, packing and shipping expenses, as e-books are created on computers, and delivered through the Internet ${ }^{\mathrm{iv}}$. The lower cost of producing and distributing e-books can mean a lower price for the consumers. Often, e-books are 20-30\% less expensive than their printed equivalents. However, as the publishers are likely to try to maximize the profit margin, they may find ways to increase the price of e-books.

- The lower cost of producing and distributing e-books affords authors of many worthy books who are not able to receive contracts from established publishers the opportunity to publish and distribute their books as e-books. They may make use of social Web sites, blogs, or e-book distribution Web sites.

Some claim that e-books are more environment-friendly than printed books. This is partially correct. E-books do not require trees to be cut down, and a lot of water to be used in creating paper. However, as pointed out in [5], e-book readers require various toxic substances to manufacture, and are not biodegradable. The disposal of the batteries used in e-book readers also poses an environmental risk. As we will see later, a dedicated e-book reader consumes far less energy than a multi-function computing device that is used as an e-book reader. This means that dedicated e-book readers require less-frequent recharging of the battery than multi-function computing devices. Therefore one may say that, for the single purpose of reading e-books, dedicated e-book readers are more environment-friendly than multi-function computing devices.

\subsection{Drawbacks}

The drawbacks of e-books over printed books are summarized as follows:

- Many people prefer the familiarity and comfort of reading printed books over e-books. For this reason, many authors prefer to have their work published in printed form.

- Some types of material, such as graphics, complex graphs, art work, etc., are simply better in printed form.

- An e-book requires an e-book reader, which is in general much more expensive than a number of printed books. If one cannot amortize the cost of the e-book reader, an e-book can be more expensive than its printed equivalent. The multi-function computing device is in general more expensive than the dedicated e-book reader. However, the facility to read e-books may be regarded as "free".

- Only a tiny fraction of all books is available as e-books. The lack of e-book tiles is an impediment to growth of the e-book market.

- The availability of e-books depends on the availability of the e-book reader on which they are stored. That is, if the e-book reader is lost or stolen, all the books on it are lost or stolen. The e-book reader may be regarded as more fragile than printed books, since it may be more susceptible to damage due to shock, high or low temperature, or water. If the e-book reader is damaged or fails, all the books on it may be lost [3]. Further, some e-books can be read only on certain e-book readers. This is because there is no standard for the file formats and DRM (digital rights management) for e-book readers. (We will discuss this further in Section 5.) 
- The LCD (liquid crystal display) screens used on multi-function computing devices that are used as e-book readers can cause eye strain from screen glare. Further, the display resolution of the screens is considerably less than the print quality of the printed books. This problem is not regarded as serious for dedicated e-book readers that use e-paper technology. (We will discuss this later.)

- E-book readers require batteries or electricity. The batteries need to be recharged.

- There is no used e-book market, so (human) readers will neither be able to recoup some of their costs by selling an unwanted title they have finished, nor buy used copies at significant discounts, as they can now easily do with printed books.

\section{E-book readers}

In this section, we will discuss the two types of e-book readers, and the architecture and features of the e-book readers.

\subsection{Types of device}

Some e-book readers are designed solely (or primarily) for storing and reading e-books. Prominent examples are Amazon's Kindle and Sony's PRS Reader. Some types of multi-function portable computing devices can also be used to store and read e-books. Prominent examples include Apple iPhone, Apple iPod Touch, and Apple iPad. Further, in terms of the technology used for the display screen, there are two types of e-book reader: one that uses the e-paper technology, and one that uses the LCD technology. E-book readers designed solely for reading e-books have adopted the e-paper technology for their screens. In this section, we will examine dedicated e-book readers and multi-function e-book readers.

\subsubsection{E-book readers that use e-paper screen}

Amazon Kindle and Sony PRS Reader are prominent e-book readers that use the e-paper screen technology. E-paper is an electronic display panel with paper-like appearance. It makes it possible to read even under direct-sunlight, and gives a near 180-degree viewing angle. It uses energy only until the text is displayed on screen; and it does not use energy to keep the text visible [7]. In other words, it draws energy only when the page turns. Nick Sheridon did the pioneering research into e-paper in the 1970s at Xerox's Palo Alto Research Center in the United States. The research has led to e-ink display in 2004. E-ink started as a spin-off company from MIT Media Lab in 1997. In 2009 it was acquired by YFY Group, Taiwan ${ }^{\mathrm{v}}$. The revenue in 2009 was about US $\$ 150$ million US. Today, most vendors of dedicated e-book readers use the e-ink display. The vendors include Amazon, Sony, Barnes \& Noble, Samsung, Hitachi, Motorola, Casio, Citizen, Hanvon, iRiver, Bookeen, Kobo, Lexar, and Plastic Logic, etc.

E-ink material consists of millions of micro-capsules with the diameter about a human hair [6]. As shown in Fig. 3, in each micro-capsule, positively charged white micro-particles and negatively charged black micro-particles are suspended in a clear dielectric fluid. When a positive electric field is applied, the white particles move to the top of the micro-capsule and the black particles to the bottom of the micro-capsule. Then the spot surface appears white. By using the inverse electric field, the black particles are pushed to the top of the micro-capsule and the spot surface looks black. Since e-ink requires almost no power to hold this segregated status, the power consumed by e-paper is very low. 
Table 1

E-book readers that use the e-paper screen

\begin{tabular}{|c|c|c|c|c|c|c|c|c|}
\hline Maker & Model & $\begin{array}{c}\text { Year } \\
\text { introduced }\end{array}$ & $\begin{array}{l}\text { Screen size } \\
\text { (inch) }\end{array}$ & $\begin{array}{l}\text { Screen } \\
\text { pixel }\end{array}$ & $\begin{array}{l}\text { Weight } \\
(\mathrm{g})\end{array}$ & $\begin{array}{l}\text { Operating } \\
\text { system }\end{array}$ & $\begin{array}{c}\text { Touch screen } \\
\text { stylus }\end{array}$ & $\begin{array}{l}\text { Wireless } \\
\text { network }\end{array}$ \\
\hline Amazon & Kindle 3 & 2010 & 6 & $600 \times 800$ & 247 & Linux & No & WiFi, 3G \\
\hline Barnes \& Noble & Nook simple touch & 2011 & 6 & $600 \times 800$ & 212 & Android & Yes & WiFi \\
\hline Sony & $\begin{array}{l}\text { Reader Pocket Edition } \\
\text { PRS-350 }\end{array}$ & 2010 & 5 & $600 \times 800$ & 155 & Linux & Yes & No \\
\hline Hanvon & WISEreader N618 & 2010 & 6 & $600 \times 800$ & 260 & WinCE & Yes & WiFi \\
\hline iRiver & Story HD & 2011 & 6 & $768 \times 1024$ & 207 & Linux & No & $\mathrm{WiFi}$ \\
\hline Bookeen & Cybook Orizon & 2010 & 6 & $600 \times 800$ & 245 & Linux & Yes & $\begin{array}{l}\text { WiFi, } \\
\text { Bluetooth }\end{array}$ \\
\hline Kobo & eReader Touch & 2011 & 6 & $600 \times 800$ & 200 & Linux & Yes & WiFi \\
\hline
\end{tabular}

Table 2

E-book reader ownership

\begin{tabular}{lccc}
\hline E-book reader & Feb 2010 & Aug 2010 & Nov 2010 \\
\hline Kindle & $68 \%$ & $62 \%$ & $47 \%$ \\
iPad & N/A & $16 \%$ & $32 \%$ \\
\hline
\end{tabular}

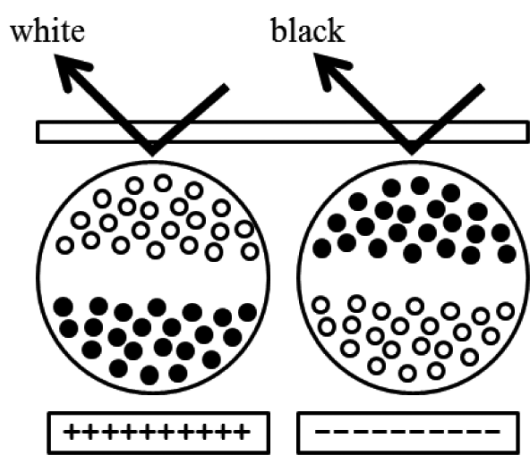

Fig. 3. e-ink micro-capsules.

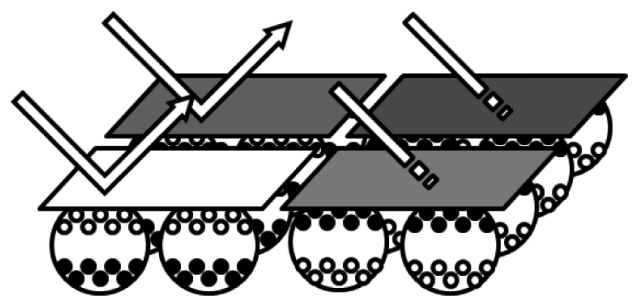

Fig. 4. e-Ink with color filter array.

For color, the latest e-ink product implements 4096 colors by adding a transparent colored filter array (CFA) in front of the black and white display. As shown in Fig. 4, The CFA consists of four sub-pixels of red, green, blue and white. If a micro-capsule is charged as white, the reflected light is colored by the filter on the top of the micro-capsule. By combining four sub-pixels, a fully colored pixel is implemented.

Table 1 compares some of the latest e-book readers that use the e-paper screen ${ }^{\mathrm{vi}}$.

\subsubsection{Tablet computers used as e-book readers}

As with PCs, cell phones, TV sets, etc., tablet computers use LCD screens. LCD can clearly display pictures and video in full color. Tablet computers with touch screen facilitate interaction. Tablet computers, especially Apple's iPad, are rapidly increasing their share of the e-book reader market. Table 2 shows this trend ${ }^{\text {vii. }}$.

Table 3 compares popular tablet computers that are used as e-book readers. Tablet computers are convenient because they can be used for a number of purposes, not just e-book reading. However, today they have the following drawbacks relative to e-book readers that use e-paper screens.

- The LCD screen is backlit, and it makes it hard to read under bright sunlight. 
Table 3

Tablet computers used as e-book readers

\begin{tabular}{lcccccccc}
\hline Maker & Model & Year & $\begin{array}{c}\text { Screen size } \\
\text { (inch) }\end{array}$ & $\begin{array}{c}\text { Screen size } \\
\text { (pixel) }\end{array}$ & $\begin{array}{c}\text { Weight } \\
\text { (g) }\end{array}$ & $\begin{array}{c}\text { Operating } \\
\text { system }\end{array}$ & $\begin{array}{c}\text { Touch } \\
\text { screen }\end{array}$ & $\begin{array}{c}\text { Wireless } \\
\text { network }\end{array}$ \\
\hline Apple $^{\text {viii }}$ & iPad2 & 2011 & 9.7 & $768 \times 1024$ & 607 & iOS & Yes & WiFi, 3G, Bluetooth \\
Samsung $^{\text {ix }}$ & Galaxy Tab10.1 & 2011 & 10.1 & $800 \times 1280$ & 565 & Android & Yes & WiFi, 3G, Bluetooth \\
Motorola $^{\mathrm{x}}$ & XOOM & 2011 & 10.1 & $800 \times 1280$ & 730 & Android & Yes & WiFi, 3G, Bluetooth \\
Barnes \& Nobel $^{\mathrm{xi}}$ & Nook Color & 2010 & 7 & $600 \times 1024$ & 450 & Android & Yes & WiFi \\
Aluratek $^{\mathrm{xii}}$ & Libre Touch & 2010 & 7 & $480 \times 800$ & 199 & Android & Yes & WiFi \\
\hline
\end{tabular}

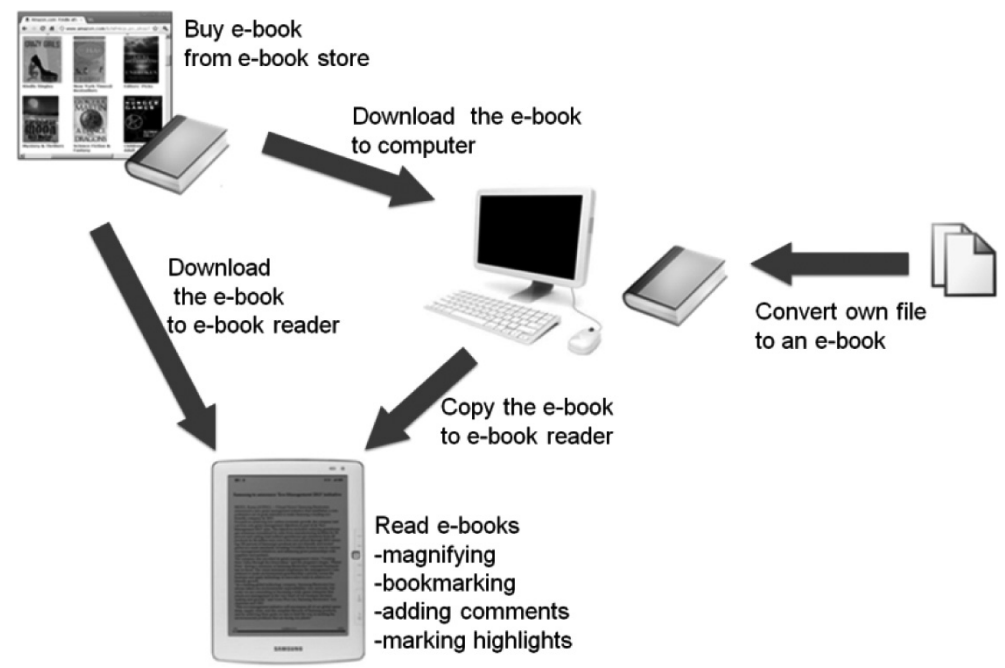

Fig. 5. Loading an e-book onto an e-book reader.

- Tablet computers use much more energy. For example, the battery in an iPad2 lasts no more than a day ${ }^{\text {xiii }}$, while that of Kindle lasts up to two months ${ }^{\text {xiv }}$.

- Tablet computers are more expensive.

\subsection{Architecture}

In this section, we describe the architecture and features of the e-book reader.

\subsubsection{Hardware and software}

As the e-book reader is in essence a handheld mobile computer, it consists of a CPU, main memory, flash memory as stable storage, input and output mechanisms, and external connections. For input, touch screen, key pad, buttons, and stylus are provided. For output, screen and speaker are provided. As discussed earlier, the screen may be e-paper or LCD. For external connection, wireless access to the Internet is provided, and USB ports are provided to connect with other computer and to allow printing of the e-book.

Figure 5 shows how an e-book is loaded onto an e-book reader. The (human) reader needs to download an e-book, either from a free download Web site, or from an e-book store. For example, Amazon.com is the e-book store for Amazon's Kindle, and iBookStore is that for Apple's iPad. Many other e-book stores, like fictionwise.com, provide e-books in various formats of the major publishers. As shown in Fig. 5, if the e-book reader can be connected to the Internet through the WiFi or the $3 \mathrm{G}$ network, the 
Table 4

Free e-book reader software

\begin{tabular}{|c|c|}
\hline Software & Description \\
\hline Calibre e-book Management-Conversion & supports a complete e-book cataloging tool with a ton of features, including \\
\hline Software ${ }^{\mathrm{xv}}$ & $\begin{array}{l}\text { library management, format conversion, RSS news feeds to e-book conversion, } \\
\text { e-book reader synchronization features, etc. }\end{array}$ \\
\hline Adobe Digital Editions ${ }^{\mathrm{xvi}}$ & $\begin{array}{l}\text { allows (human) readers to read EPUB and PDF files, as well as Adobe } \\
\text { Flash(SWF) }\end{array}$ \\
\hline $\begin{array}{l}\text { Kindle Apps for PC, Mac, Android, iPad, } \\
\text { IPhone, Blackberry }\end{array}$ & provides access to the Kindle Book Store \\
\hline Sony Reader Library software ${ }^{\mathrm{xviii}}$ & $\begin{array}{l}\text { supports all the same files as Sony Readers, Mac and apps for iPhone and } \\
\text { Android }\end{array}$ \\
\hline Barnes and Noble Nook Apps ${ }^{\mathrm{xix}}$ & $\begin{array}{l}\text { access B\&N's e-book store and download from a mobile device's browser and } \\
\text { side-load other DRM-free EPUB e-books }\end{array}$ \\
\hline MobiPocket Reader ${ }^{\mathrm{xx}}$ & $\begin{array}{l}\text { supports MOBI and PRC e-books, as well as unencrypted PDB files and is } \\
\text { available on a variety of platforms. }\end{array}$ \\
\hline Microsoft Reader ${ }^{\mathrm{xxi}}$ & $\begin{array}{l}\text { supports only LIT format, and user can't import files. It isn't particularly user- } \\
\text { friendly, but supports a lot of features. }\end{array}$ \\
\hline Stanza ${ }^{\mathrm{xxii}}$ & $\begin{array}{l}\text { provides software to read e-books on user's PC or Mac and share with user's } \\
\text { iPhone, iPod Touch, and Kindles. }\end{array}$ \\
\hline Plucker ${ }^{\mathrm{xxiii}}$ & $\begin{array}{l}\text { provides program for Palm OS base devices, Pocket PC, and Other cell phones } \\
\text { and PDAs. It is an Open Source offline HTML viewer }\end{array}$ \\
\hline
\end{tabular}

e-book is downloaded to the e-book reader directly. Otherwise, it is first downloaded to a computer connected to the Internet and then copied to the e-book reader though a USB cable or a memory card. When the e-book reader is connected to the computer, the contents of an e-book or the reading list (i.e., the entire collection of e-books) on both devices can also be synchronized.

The e-book reader needs various software, including the e-book viewer for viewing the e-book, document manager for managing the reading list, Web browser, Acrobat Reader, document compression and decompression software, etc., and the operating system to manage all these software. The e-book viewer can include options, such as text-to-speech translator, dictionary manager, etc.

There are several free e-book reader software which make it possible for (human) readers to read e-books on desktop computers or smart phones without the e-book reader hardware. Table 4 provides brief descriptions of some of them.

\section{File formats}

For any document to be read on an e-book reader, the document's file needs to be converted to the e-book format of the e-book reader. The conversion can be done by stand-alone utilities or by Web services on the Internet. The file formats include ASCII, TXT, RTF, FB2, PDF, HTML, ePUB, AZW, Mobipocket, Microsoft LIT, etc. The most widely adopted formats are PDF, AZW, and ePUB.

The PDF (portable document format) is supported by most e-book readers, and so does not require conversion. It is an open standard file format created by Adobe Systems [1]. It can be viewed on a variety of hardware and software platforms, and has become very common on the World Wide Web.

The AZW format is the proprietary format used by Amazon on the Kindle. Amazon acquired Mobipocket, and the AZW format is basically the Mobipocket format. The Mobipocket format is a binary format for the distribution of e-books and supports most features of standard HTML to format and layout text and images. It is based on the Open e-book Publication format specified by the IDPF (International Digital Publishing Forum).

The ePUB format is an open standard used in many e-book readers other than the Kindle. The ePUB format is also specified by the IDPF. In the ePUB format, a means of representing, packaging and 
encoding structured and semantically enhanced Web content are defined for distribution in a single-file format $^{\mathrm{xxiv}}$. ePUB has been widely adopted as the format for e-books for almost all e-book readers except Amazon's Kindle. iBooks, which is the built-in e-book reader application of iPad, also uses the ePUB format.

\section{$D R M$}

E-book readers protect the e-books using DRM (digital rights management) technology. DRM refers to any technology-based scheme that controls access to copyrighted digital content. In e-book readers, DRM is typically used to restrict copying, printing and sharing of e-book [8]. The authorization to view an e-book is assigned to devices as well as users. The authorization information includes information about the user, devices, access type, and access duration. The authorization information is registered with the central server of an e-book reader vendor. DRM allows libraries to lend e-books for limited periods [7]. Often, DRM prohibits the printing of e-books.

Three main e-book DRM schemes are from Amazon, Adobe and Apple. Amazon's DRM is based on the Mobipocket encryption scheme, and applied to Amazon's AZW format files [8]. Apple's FairPlay DRM has been used in QuickTime multimedia software, iTunes Store, and App Store [11]. For e-books, iBookStore is Apple's ePUB content market, and the FairPlay DRM is applied to the ePUB format files. Only Apple's iBooks application on iOS devices can read the FairPlay DRM format.

The Adobe e-book platform includes four applications: Adobe InDesign CS5, Adobe Content Server 4, Adobe Reader Mobile 9 SDK, and Adobe Digital Editions software. Sony and many other e-book reader vendors use the Adobe DRM. Adobe InDesign CS5 is used for e-book publishers to create e-book files in ePUB or PDF format; and Adobe Content Server 4 encrypts the e-book files for retailers to securely distribute them to consumers. E-book reader vendors may develop software for their devices to read the encrypted e-book files by using Adobe Reader Mobile 9 SDK. Consumers can read e-book files by downloading Adobe Digital Editions software to their desktop computers.

\subsection{Features}

The functions of e-book readers are fairly extensively listed in [2], which are grouped into three categories: customizing display options, adding personal annotation, and supporting utilities. For completeness, we summarize them in this section.

For the customizable display options, the size and type of font and the number of words per line can be changed, and the screen rotation can be selected as portrait or landscape. The size of an image can also be adjusted.

For the personal annotation, a bookmark can be placed on any page of e-books. Even if the number of the bookmarked page is changed by adjusting the font size or the number of words per line, the bookmarked location is correctly adjusted to the position on the new page. In addition, a passage on a page can be highlighted. These annotations are not only stored in the e-book reader but also usually managed by a centralized service in order to share the annotations in the files on other devices, such as a smart phone [9].

For the utilities, text-to-speech, embedded dictionary, searching and Web browsing are included. While text-to-speech is playing, the pages are turned automatically. The rate of speech is usually controllable. By using the embedded dictionary, a particular word can be looked up without leaving the page the (human) reader is reading. Further, the (human) reader can search a term or a phrase from the e-book he is reading or the reading list (e-books in the e-book reader). With e-book readers with network connection, even Web pages or e-books in e-book stores can be searched, and general Web browsing is supported. A part of the comparison of e-book readers' utilities given in Wikipedia is shown in Table 5. 
Table 5

Utilities supported on e-book readers

\begin{tabular}{lccccc}
\hline Maker & Model & Text-to-speech & Embedded dictionary & Search & Web browser \\
\hline Amazon & Kindle 3 & Yes & Yes & Yes & Yes \\
Barnes \& Noble & Nook Simple Touch & No & Yes & Yes & No \\
Sony & Reader Pocket Edition PRS-350 & No & Yes & Yes & No \\
Hanvon & WISEreader N618 & Yes & No & Yes & Yes \\
iRiver & Story HD & No & Yes & Yes & No \\
Bookeen & Cybook Orizon & No & No & Yes & Yes \\
Kobo & eReader Touch & No & Yes & Yes & Yes \\
Apple & iPad2 & Yes & Yes & Yes & Yes \\
Samsung & Galaxy Tab 10.1 & Yes & Yes & Yes & Yes \\
Motorola & XOOM & Yes & Yes & Yes & Yes \\
Barnes \& Nobel & Nook Color & No & Yes & Yes & Yes \\
Aluratek & Libre Touch & No & No & Yes & Yes \\
\hline
\end{tabular}

\section{E-book market}

In this section, we examine the status of the market adoption of e-books, and the e-book industry ecosystem.

\subsection{Market adoption}

With the release in the 1990s of Bookman by Sony, Digitalbook by NEC, RocketBook by Nuvomedia, etc., the e-book started receiving attention. In 2000 large bookstores and publishing companies, such as Barnes \& Noble and Random House, entered the market. Stephen King's novel, "Riding the Bullet", had 400,000 downloads in the first 24 hours $^{\mathrm{xxv}}$. However, the e-book market failed to take off for various reasons. In 2000, IT bubble burst. The quality of the initial products and services did not meet customers' expectations. The e-paper technology was in its infancy. Many publishing companies were concerned about e-books cannibalizing the sales of the printed books.

Amazon's release of Kindle in 2007 revitalized the e-book market. Kindle adopted the improved e-paper screen, and provided WiFi connection for downloading e-books. Amazon made 88,000 titles available for Kindle. Amazon also set the price of many e-books at US\$9.99 (one half to one third of the price of printed books). The launch of Kindle and Nook by Barnes \& Noble in 2009, and iPad by Apple in 2010 catalyzed the growth of the e-book market. Amazon was able to sell close to 3 million Kindles in 2009 ${ }^{\text {xxvi }}$. Kindle Books within Amazon's Kindle Store had 420,000 different titles by big and small publishers as of July 2010. The number of vendors offering dedicated e-book readers increased to more than 20. The price of e-book reader has been reduced. Yankee Group, a market research company, foresees that e-book reader sales will increase from 6 million units in 2010 to 25 million units in 2013, and that the price of an e-book reader will drop from US\$213 in 2010 to US\$131 in $2013^{\mathrm{xxvii}}$.

Barnes \& Noble, which has the biggest market share of off-line book market, possess more than 1 million e-book titles as of July 2010. Borders also have over 1 million e-books. The Kindle Books now has over 760,000 titles. Apple formed partnership with the big-6 publishers (Penguin Group, HarperCollins, Macmillan, Random House, Hachette Book Group, Simon \& Schuster) to sell their ebook titles on iBook Storexxviii. iBook Store has more than 200,000 titles in 2010 a leading academic publisher, offers 85,000 e-books through its Web site. Other notable e-book stores include eBooks.com, Foyles, Penguin, Random House US and UK, Waterstones, Google Books, etc. [7].

Michael Hart launched the world's first "digital library" project, named Project Gutenberg in 1971 at the University of Illinois. The vision was to create a free electronic repository of classic books in the 


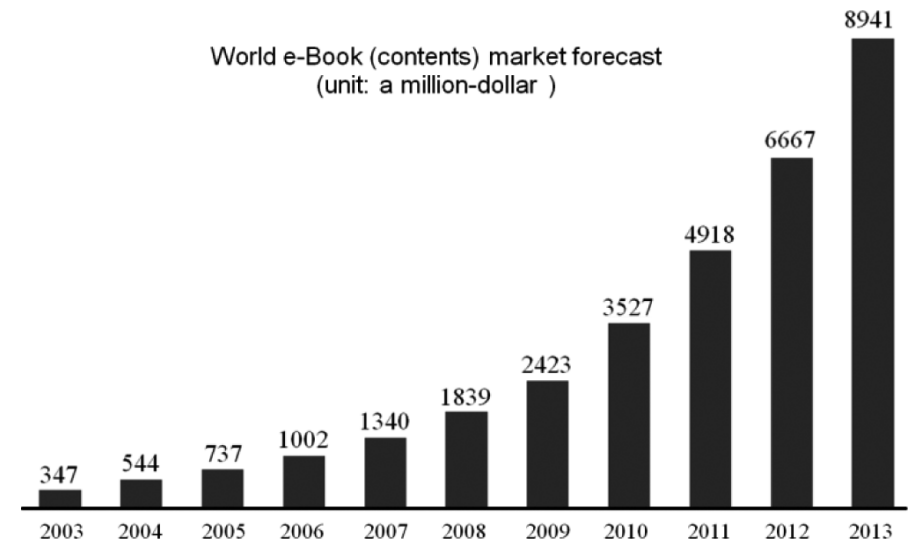

Fig. 6. World e-book market forecast.

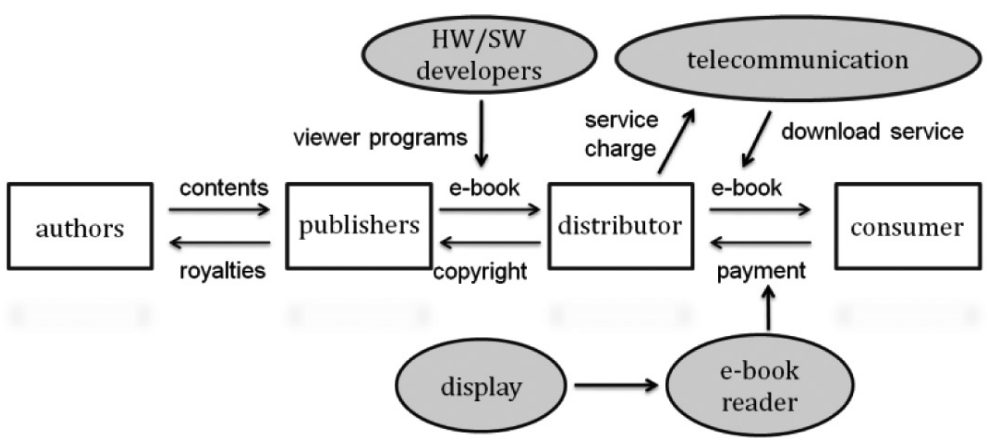

Fig. 7. E-book industry ecosystem.

public domain, that is, books that are no longer copyright-protected. The project is still ongoing. As of June 2011, Project Gutenberg claims to have over 36,000 items in its collection. The e-books are available in various file formats, including ASCII, HTML, PDF, ePUB, MOBI, and Plucker ${ }^{\mathrm{xxx}}$.

The market share for e-books is still tiny compared to that for printed books. However, it is expected to grow fast. A recent survey of publishing executives suggests that within just three years, half of all books sold will be e-books. Figure 6 shows the world e-book market forecast by PriceWaterhouseCooper ${ }^{\mathrm{xxxi}}$. PWC foresees that the e-book market will grow at an annual growth rate of $37.2 \%$ to US $\$ 8.9$ billion by 2013. The market share for e-books is expected to grow to $5 \%$ by 2013.

\subsection{Industry ecosystem}

Figure 7 shows the ecosystem of the e-book industry. The e-book industry ecosystem consists of six key participants: authors, publishers, distributors, consumers, e-book reader vendors, and hardware and software providers for e-book readers. Below, we summarize the role of each of the participants.

- Authors create contents.

- Publishers produce books, in either or both the printed form or e-book form.

- Distributors collect e-book contents and make them available for downloading by consumers. Consumers may be individuals or organizations (e.g., libraries). Distributors include those who convert public-domain printed books to e-books. The Gutenberg Project is an example of a distributor. Large 
publishers distribute e-books themselves, while the majority of small and middle-size publishers do not.

- Telecommunication companies provide wireless network access to distributors to make it possible for (human) readers to download e-books.

- E-book reader vendors develop and sell e-book readers.

- Hardware developers include the e-ink company that provides the screens for dedicated e-book readers, and the usual computer industry hardware providers. Software developers provide software for e-book readers, and include those who create free software. They also provide software for converting e-book files to different formats.

\section{Issues}

There are various issues facing the e-book market. They include technology problems, publishers' revenue concerns, and ownership question. In this section, we examine each of these.

Perhaps the most serious technology problem is the current limitations of color e-paper. The current e-paper technology is weak in supporting color and video. Since it takes at least 120 milliseconds to update the status of a micro-capsule, video cannot be played smoothly on e-paper. The quality of the color is still not good enough compared to LCD.

Another technology issue is the standards. The absence of a single universal standard is an issue in any area. Often, there have been two standards, and the customers have to simply choose one or the other. Just as customers have to choose between Apple and Android in the area of smart phones, for now it appears that customers of e-books have to choose between Amazon and the rest. Amazon has its own proprietary file format and DRM, while many other e-book reader vendors have embraced the ePUB open standard file format and the Adobe Digital Editions and Content Server4 DRM.

Publishers are naturally concerned that e-books, rather than becoming a new revenue stream, may cannibalize their printed book revenue. According to Nielsen BookScan data ${ }^{x x x i i}$, the growth in e-book sales seems to cannibalize the sales of printed books only in limited genres, such as romance and sciencefiction. However, how the market will play out is difficult to predict. It is likely that e-books will disrupt the book market, and in order to remain competitive in the changing market, the publishers must develop new business models, pricing strategy, marketing strategy, and technology. For example, publishers may sell e-books chapter by chapter, as new chapters are completed. They may have distributors rent out e-books for limited periods. They may make available sample pages of e-books to bookseller Web sites to help stimulate demand [10]. Further, they need to develop software tools that help consumers discover e-books and help authors with book promotion through the Web. For example, the New York Times recently introduced an e-book best seller list as a tool to promote e-book sales. Further, many e-book discovery tools have been proposed recently ${ }^{\mathrm{xxxiii}}$.

Publishers must find the right pricing strategy for e-books. There are some e-book publishers who handle distribution themselves, and there are others who engage third-party distributors. There have been continuing debates and corporate fights between publishers and distributors over setting the price for e-books. For example, from the beginning Amazon forced publishers to accept a much lower list price for their e-books than printed books in order to increase the sale of e-books. Although this pricing strategy helped to seed the e-book market, it could set the consumers' expectation for low pricing for e-books, leading to lower revenues for publishers. Apple created the agency model for selling music for music labels. This model has been adopted by Amazon for selling e-books. Under the agency model, the publisher sets the price of e-books and the agency, such as Apple, sells e-books and takes its cut. 
However, under this model, to account for the agency's cut, the publishers may set the prices higher to start with. Although this may make the publishers happy, there may be a backlash from consumer unhappiness.

"Buying" an e-book is more like renting or leasing it. In July 2009, Amazon remotely removed George Orwell's 1984 and Animal Farm from customers' Kindles without any agreement with their customers $^{\text {xxxiv }}$. Although Amazon was simply honoring a request by the publisher and refunded the customers, someone pointed out that it was like "a person buying a book in an offline bookstore, then at night the bookstore having an employee break into the customer's home to retrieve the book, and leaving some cash on the table". Access to the e-book may be removed by the publisher, e-book reader vendor, etc. Currently, buying an e-book on the Kindle does not seem to mean that the buyer "owns" that book. The buyer cannot use the e-book in the ways in which he could use a printed book; he cannot lend the e-book to a friend or re-sell it or even keep it as long as he wants.

\section{Prognosis and conclusion}

There are two types of e-book readers: a dedicated e-book reader, and a multi-function computing device. Some people seem to think that multi-function devices, such as iPad, will kill off dedicated e-book readers. In the distant future, that may come to pass. However, for the foreseeable future, we expect that the two types of e-book reader will co-exist. Two major advantages for the dedicated e-book reader are the e-paper screen that allows reading even under the direct sunlight, and the much longer battery life. Further, the dedicated e-book readers may evolve to add functions beyond reading e-books, for example, MP3 music playing.

We expect that e-books and printed books will coexist for a long time, and replacement of printed books by e-books will be gradual. Further, we expect that publishers will find business models and pricing strategy so that their overall revenues will increase.

\section{Acknowledgments}

This work was supported by Gachon University Research Fund in 2012, and by Basic Science Research Program through the National Research Foundation of Korea (NRF) funded by the Ministry of Education, Science and Technology (2012-0004177).

\section{References}

[1] ISO 32000-1:2008 - Document management - Portable document format - Part 1: PDF 1.7, 2008.

[2] Y. Li, Dedicated E-reading Devices: the State of the Art and the Challenges, Design of Electronic Text 1(1) (2008), 1-7.

[3] B. Park, Y. Chung and J. Park, Recovery of flash memories for reliable mobile storages, Mobile Information Systems $\mathbf{6}(2)$ (2010), 177-191.

[4] S. Caballe, F. Xhafa and L. Barolli, Using mobile devices to support online collaborative learning, Mobile Information Systems 6(1) (2010), 27-47.

[5] L. Siegel, Should we switch to reading books online? The Observer Magazine, 2009.

[6] B. Comiskey, J.D. Albert, H. Yoshizawa and J. Jacobson, An Electrophoretic Ink for All-printed Reflective Electronic Displays, Nature 1998, 1998, pp. 253-255.

[7] J. Heikenfeld, P. Drzaic, J. Yeo and T. Koch, A critical review of the present and future prospects for electronic paper, Journal of the Society for Information Display 19(2) (2011), 129-156.

[8] J.E. Cohen, DRM and privacy, ACM Communication 46(4) (2003), 46-49. 
[9] Z. Ma, D.L. Silver and E.M. Shakshuki, User profile management: reference model and web services implementation, Int J Web and Grid Services 6(1) (2010), 1-34.

[10] E. Gardiner and R.G. Musto, The Electronic Book, The Oxford Companion to the Book, Oxford University Press 3 (2010), 54-56.

[11] D. Geer, Digital rights technology sparks interoperability concerns, IEEE Computer 37(12) (2004), 20-22.

[12] C. Harris, The truth about ebooks, School Library Journal 55(6) (2009), 18.

\section{List of URLs}

${ }^{\mathrm{i}}$ http://www.ebookswriter.com

ii http://www.chrysanth.com

iii http://www.antssoft.com

${ }^{\mathrm{iv}} \mathrm{http} / / / \mathrm{www}$.archive.org/details/millionbooks

${ }^{\mathrm{v}} \mathrm{http}: / /$ www.eink.com/

${ }^{\mathrm{vi}} \mathrm{http} / / /$ en.wikipedia.org/wiki/Comparison_of_e-book_readers

${ }^{\mathrm{vii}}$ http://www.investorplace.com/2010/11/apple-ipad-vs-amazon-kindle-e-reader-market/

viii http://www.apple.com/ipad/specs/

${ }^{\mathrm{ix}} \mathrm{http}: / / \mathrm{www}$. samsung.com/global/microsite/galaxytab/10.1

${ }^{\mathrm{x}} \mathrm{http} / / / \mathrm{www} . \mathrm{motorola.com/}$

${ }^{\mathrm{xi}} \mathrm{http} / / / \mathrm{www}$. barnesandnoble.com/u/nook/379003208/

xii http://www.aluratek.com

xiii http://www.macworld.com.au/print/26489

${ }^{\mathrm{xiv}} \mathrm{https} / / /$ kindle.amazon.com

${ }^{\mathrm{xv}} \mathrm{http}$ //calibre-e-book.com

${ }^{\mathrm{xvi}}$ http://www.adobe.com/products/digitaleditions/

xvii http://www.amazon.com/b/?node=133141011

xviii http://ebookstore.sony.com

${ }^{x i x}$ http://www.barnesandnoble.com/u/NOOK-Apps/379003212

${ }^{\mathrm{xx}} \mathrm{http}: / /$ www.mobipocket.com

${ }^{\mathrm{xxi}}$ http://www.microsoft.com/reader/

${ }^{x x i i}$ http://www.lexcycle.com

xxiii http://www.plkr.org

xxiv http://idpf.org/epub

${ }^{\mathrm{xxv}} \mathrm{http}: / /$ www.planetebook.com/mainpage.asp?webpageid=39

xxvi http://www.businessweek.com/the_thread/techbeat/archives/2010/01/amazon_ceo_mill.html

xxvii http://www.zdnet.com/blog/btl/kindle-vs-nook-the-price-war-is-on-e-reader-shipments-to-surge/36066

xxviii http://www.newyorker.com/reporting/2010/04/26/100426fa_fact_auletta

${ }^{\mathrm{xxix}} \mathrm{http}: / / \mathrm{ww}$.thebookseller.com

${ }^{\mathrm{xxx}} \mathrm{http}: / /$ www.gutenberg.org

${ }^{\mathrm{xxxi}} \mathrm{http} / / / \mathrm{www} . \mathrm{pwc} . \mathrm{com}$

xxxii http://www.endersanalysis.com/news

xxxiii http://www.bookglutton.com

${ }^{\text {xxxiv }}$ http://artsbeat.blogs.nytimes.com/2009/07/17/some-e-books-are-more-equal-than-others/

Chulyun Kim is currently an assistant professor at Gachon University (formerly Kyungwon University), in S. Korea. Before that, he was the Chief Technical Officer at Ntros, Korea, a technical staff member at ICUBE, Korea and a research assistant at National Center for Supercomputing Applications, Illinois, US. He received a BS degree in computer engineering, an MS degree in cognitive science, and a $\mathrm{PhD}$ degree in electrical engineering and computer science from Seoul National University, Korea. He received a Microsoft Research Asia Fellowship in 2004. His research has been in the areas of data mining, Web mining, cloud computing, stream data processing, and interdisciplinary informatics.

Ok-Ran Jeong is an assistant professor with the Department of Software Design and Management at Gachon University (formerly Kyungwon University) in S. Korea. She was a research professor with the School of Information and Communication Engineering at Sungkyunkwan University, Korea. Before that, she was a visiting scholar in the Department of Computer Science at the University of Illinois at Urbana-Champaign, and, a post-doctoral researcher in the Center for e-Business Technology in Seoul National University. She received a Ph.D. in computer science from Ewha Womans University. Her research interests include Web technology, Web architecture and applications. 
Jaehyuk Choi is currently an assistant professor at the Dept. of Software Design \& Management at Gachon University (formerly Kyungwon University) in S. Korea. He received a Ph.D. degree in electrical engineering and computer science from Seoul National University, Korea, in 2008. He was with the Real-Time Computing Laboratory (RTCL) at The University of Michigan, Ann Arbor, U.S.A. as a postdoctoral researcher from Dec. 2009 to Feb. 2011. His current research interests include wireless/mobile networks with emphasis on wireless LAN/MAN/PAN, vehicular networks, network management, next-generation mobile networks, cognitive radios, data link layer protocols, and cross-layer approaches.

Won Kim is a Professor and Vice President of Gachon University (formerly Kyungwon University) in S. Korea. He served as Chair of ACM SIGKDD and ACM SIGMOD, and Editor-in-Chief of ACM Transactions on Internet Technology and ACM Transactions on Database Systems. He is one of the pioneers of object-oriented database systems, object-relational database systems, and federated database systems. His current interests include social media, safer use of the Internet, and cloud computing. 

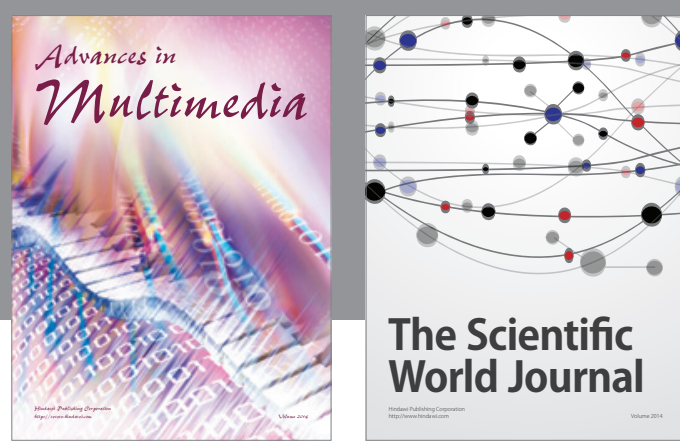

The Scientific World Journal
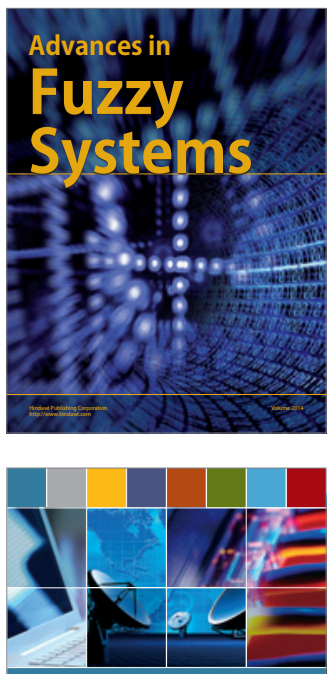

Computer Networks and Communications
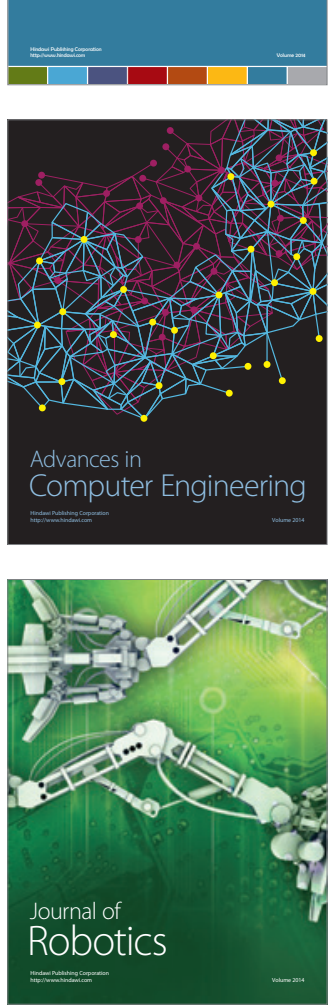
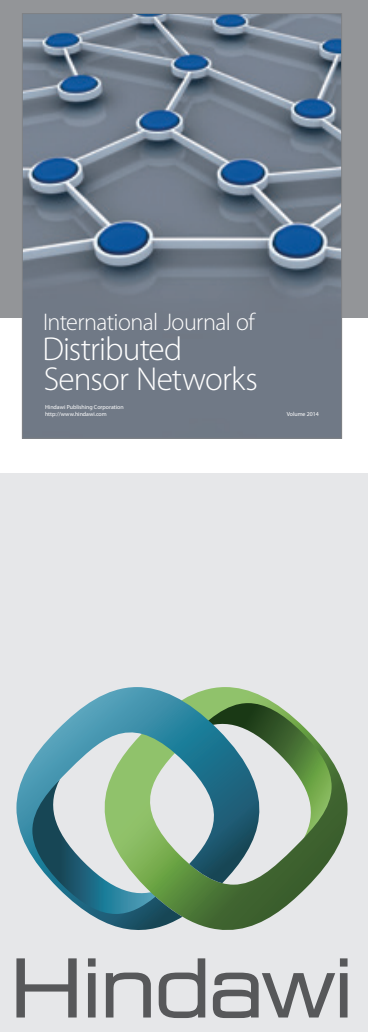

Submit your manuscripts at

http://www.hindawi.com
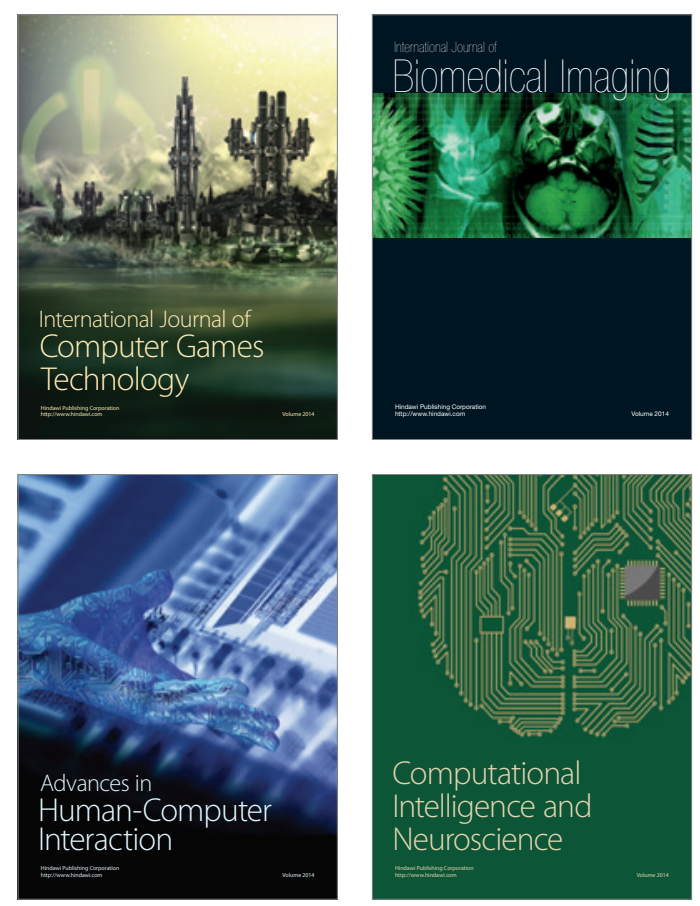
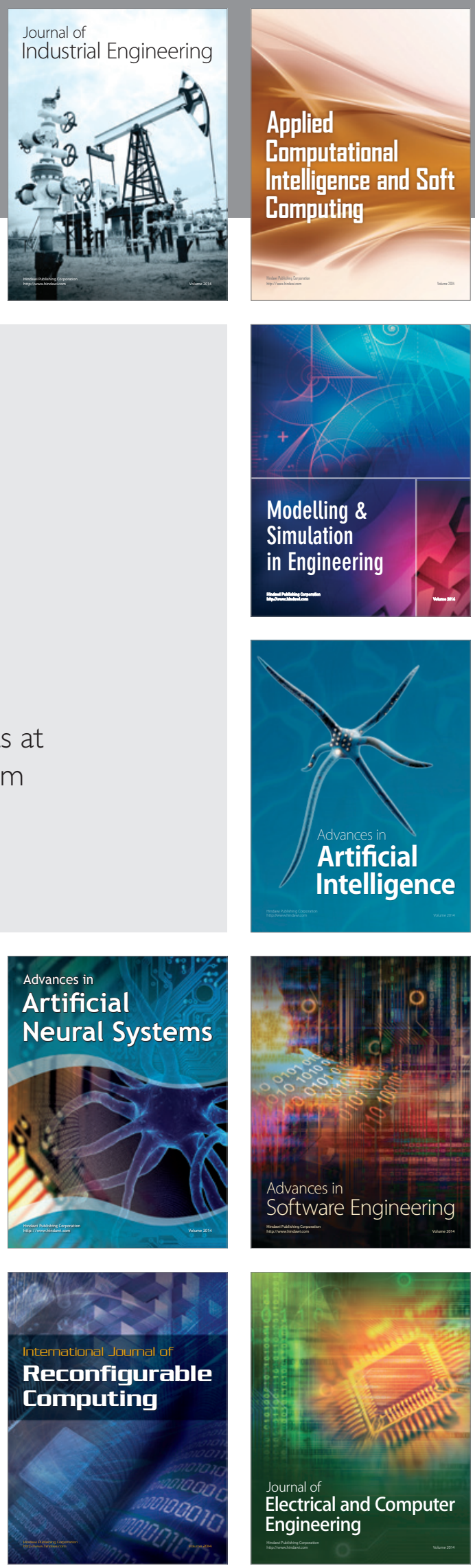